\title{
Pollination dynamics in a Douglas-fir seed orchard as revealed by pedigree reconstruction
}

\author{
Ben SK LAI ${ }^{1}$, Tomas FUNDA ${ }^{1,2}$, Cherdsak LIEWLAKSANEEYANAWIN ${ }^{1}$, Jaroslav KLÁPŠTĚ1,2, \\ Annette VAN NIEJENHUIS ${ }^{3}$, Cathy COOK ${ }^{3}$, Michael U STOEHR ${ }^{4}$, Jack Woods ${ }^{5}$, \\ Yousry A EL-KASSABY ${ }^{1 *}$ \\ ${ }^{1}$ Department of Forest Sciences, Faculty of Forestry, The University of British Columbia, 2424 Main Mall, Vancouver, \\ British Columbia, V6T 1Z4 Canada \\ ${ }^{2}$ Department of Dendrology and Forest Tree Breeding, Faculty of Forestry and Wood Sciences, Czech University of Life Sciences Prague, \\ Kamýcká 129, 16521 Praha 6, Czech Republic \\ ${ }^{3}$ Saanich Forestry Centre, Western Forest Products Inc, 8067 East Saanich Road, Saanichton, British Columbia, V8M 1K1 Canada \\ ${ }^{4}$ British Columbia Ministry of Forests and Range, Research Branch, Victoria, British Columbia, V8W 9C2 Canada \\ ${ }^{5}$ SelectSeed Company Limited, 3370 Drinkwater Road, Duncan, British Columbia, V9L 5Z2 Canada
}

(Received 18 November 2009; accepted 31 March 2010)

Keywords:

seed orchard /

DNA fingerprinting /

pedigree reconstruction /

mating dynamics /

Pseudotsuga menziesii

\begin{abstract}
- Pollination dynamics was studied in a Douglas-fir (Pseudotsuga menziesii (Mirb.) Franco) seed orchard using 8 nuclear microsatellite markers and pedigree reconstruction.

- The seed orchard consisted of 49 parents (clones). Cone-crop management included bloom delay and supplemental mass pollination (SMP) using 12 internal and 4 external pollen donors.

- A random sample of 801 bulk seeds was genotyped for both haploid megagametophyte and corresponding diploid embryo.

- Using the parental population's multilocus genotypes, full pedigree reconstruction generated all the information needed to estimate the maternal, paternal, and parental reproductive success, selfing, pollen contamination, and pollination success of the 4 external pollen donors.

- Maternal, paternal, and parental reproductive success varied with $80 \%$ of gametes being produced by 23,45 , and $37 \%$ of the orchard's parents, respectively, resulting in a drastically reduced effective population size as compared to the census number (14 vs. 53).

- Selfing, pollen contamination, and aggregate SMP success (internal and external) were estimated to be $15.2,10.4$, and $15.0 \%$, respectively.

- Full pedigree reconstruction was effective in unraveling the orchard's pollination dynamics and both female and male reproductive success.
\end{abstract}

\section{INTRODUCTION}

Seed orchards are an essential component of most forest tree improvement programs which consists of multiple populations including base populations where phenotypic selections are made, breeding populations where mating, testing, and genotypic selection are concentrated, and deployment populations (production population/seed orchards) where genetically improved seed are produced (Namkoong et al., 1988). Breeding populations are managed to maintain higher levels of genetic variability for sustained long-term genetic response, while capturing genetic gain is the sole function of production populations (Namkoong et al., 1988). Thus, they represent the linkage between breeding and silviculture activities; thus, their

*Corresponding author: y.el-kassaby@ubc.ca genetics and the quality of their seed crops should be given increased attention (El-Kassaby, 1992).

Seed orchards were expected to function as perfect panmictic populations (Eriksson et al., 1973); however, substantial research has been dedicated to illustrate that this assumption is actually never met, and management practices had to be devised to overcome or lessen the impact of this violation (El-Kassaby and Askew, 1998). Non-random mating leads to changes in allelic and genotypic frequencies in orchards' crops and ultimately results in unreliable estimates of their expected genetic gain and diversity.

Two major seed orchard management techniques; namely, bloom delay (Silen and Keane, 1969) and supplemental mass pollination (SMP) (Wakeley et al., 1966) are commonly practiced to artificially interfere with the orchard's natural 
pollination. Bloom delay involves the application of an overhead fine water mist during later parts of winter and early spring to slow heat sum accumulation, thus delaying and effectively isolating the orchard's reproduction and thereby reducing the exposure to pollen migration from external pollen sources (Silen and Keane, 1969). This technique has proven to be effective in delaying (Fashler and Devitt, 1980) and compacting reproductive phenology resulting in improved panmixia (Fashler and El-Kassaby, 1987), reduced pollen contamination (El-Kassaby and Ritland, 1986), and increased outcrossing rate (El-Kassaby and Davidson, 1990, 1991). SMP involves the broadcast application of viable pollen to nonisolated receptive strobili to increase the gametic representation of desirable genotypes in seed crops. This technique was also proven effective in facilitating mating among reproductively asynchronous parents (El-Kassaby et al., 1988), reducing the effect of outside pollen contamination (Askew, 1992; El-Kassaby and Ritland, 1986; Stoehr et al., 1998), and increasing seed set and outcrossing, particularly for early and late reproductive phenology classes where the within-orchard pollen cloud density was low (El-Kassaby and Ritland, 1986; El-Kassaby et al., 1990). SMP success rate was reported to range between 4\% in Scots pine (Yazdani et al., 1986) and $80 \%$ in loblolly pine (Bridgwater et al., 1987). The combined effect of these techniques resulted in an increased seed yield, enhanced matings among orchard's parents, and reduced pollen contamination (El-Kassaby and Davidson, 1990; El-Kassaby et al., 1990).

Numerous mating system and gene flow studies, mainly using allozyme markers, were conducted on seed orchard populations of many species (references herein). While informative, the low resolution of allozymes did not allow a clear depiction of the orchards' pollination dynamics, particularly estimating parental gametic contribution. The availability of DNA molecular markers, with their increased resolution power, facilitated more in-depth investigations of seed orchards' pollination dynamics. For example, Stoehr et al. (1998) and Stoehr and Newton (2002) exploited variability in a few chloroplast DNA hotspots and developed markers for tracing pollen in Douglas-fir (Pseudotsuga menziesii (Mirb.) Franco) and lodgepole pine (Pinus contorta Dougl. ex Loud.) seed orchards; however, these markers did not produce the high resolution required to unambiguosly identify every parent in the studied orchards. Microsatellites (SSRs), with their codominant nature and high variability, became the markers of choice for paternity analyses and their use in conifer species' seed orchards has provided the needed resolution to understanding pollination dynamics at a level that had never been observed before (Funda et al., 2008; Hansen and Kjaer, 2006; Moriguchi et al., 2004; 2005; Slavov et al., 2005).

Understanding of orchards' pollination dynamics, particularly the parental reproductive success, selfing rate, level of pollen contamination, and the success rate of pollen augmentation is essential for the correct determination of both the genetic gain and diversity of seed crops. These parameters are vital in the development of effective population management practices needed for delivering the genetic gain attained through breeding to future forests. In this study, we investi- gated the pollination dynamics in a Douglas-fir seed orchard using eight nuclear microsatellite markers and reconstructed pedigree using a random sample of bulk seed (i.e., unknown maternal or paternal parents). The pedigree reconstruction provided the information needed for estimating maternal, paternal, and parental reproductive success, selfing rate, rate of pollen contamination, genetic diversity, and the effectiveness of management techniques such as bloom delay and SMP.

\section{MATERIALS AND METHODS}

\subsection{Seed orchard population and seed sampling}

We studied a second generation, clonal seed orchard consisting of 49 parents (including 4 clones representing 2 full-sib families and 4 parent-offspring) selected from the British Columbia Ministry of Forests and Range's low elevation coastal Douglas-fir breeding program. The orchard is located on the Saanich Peninsula, southern Vancouver Island, Saanichton, British Columbia (latitude $48^{\circ} 35^{\prime} \mathrm{N}$, longitude $123^{\circ} 24^{\prime} \mathrm{W}$, elevation $50 \mathrm{~m}$ ) and was established in 1990 following the permutated neighbourhood design for allocating clones and their ramets along the orchard's grid (Bell and Fletcher, 1978). The studied seed crop (2005) was produced using both bloom delay and SMP treatment with viable pollen from 16 genotypes consisting of 4 external and 12 internal donors. The SMP was applied on 40 orchard clones with visits ranging from one to four times per ramet.

During the fall of 2005, young vegetative buds were sampled from the orchard's parental population (49 parents) as well as the 4 external parents used for SMP treatment. A total of 149 ramets were sampled (average 3 ramets per clone) representing the orchard's parental population. Multiple ramets per clone were sampled to investigate the presence/absence of labeling errors. Sampled vegetative buds were immediately placed on ice, shipped to the University of British Columbia and stored at $-80^{\circ} \mathrm{C}$ until DNA extraction. Additionally, a random sample of bulk seed (unknown parentage) of the 2005 seed crop was obtained from the British Columbia Ministry of Forests and Range's Tree Seed Centre and was stored at $4{ }^{\circ} \mathrm{C}$ until used.

\subsection{Microsatellite genotyping}

Seeds were germinated using the protocol described in Edwards and El-Kassaby (1995) and dissected following the suggestions of Krutovskii et al. (1997). Seeds were dissected and their diploid embryos and corresponding haploid megagametophytes were separated and stored at $-80^{\circ} \mathrm{C}$ until DNA extraction. DNA was extracted from all sampled vegetative buds of 49 orchard parents and 4 external pollen donors and from the embryo-megagametophyte pairs using the method of Doyle and Doyle (1990). DNA samples were amplified in a GeneAmp 9700 thermal cycler (Perkin-Elmer, Foster City, CA) following the recommendations of Slavov et al. (2004) and were genotyped using eight independent Douglas-fir microsatellite markers (PmOSU_1F9, PmOSU_3D5, PmOSU_2G12, PmOSU_2D4, PmOSU_3G9, PmOSU_3F1, PmOSU_2C2, and PmOSU_3B9), developed and tested for Mendelian segregation and linkage by Slavov et al. (2004). DNA amplicons were loaded in $25 \mathrm{~cm}$ long, $0.4 \mathrm{~mm}$ thick, 6\% (Long Ranger ${ }^{\mathrm{TM}}$ ) polyacrylamide gels and separated by 


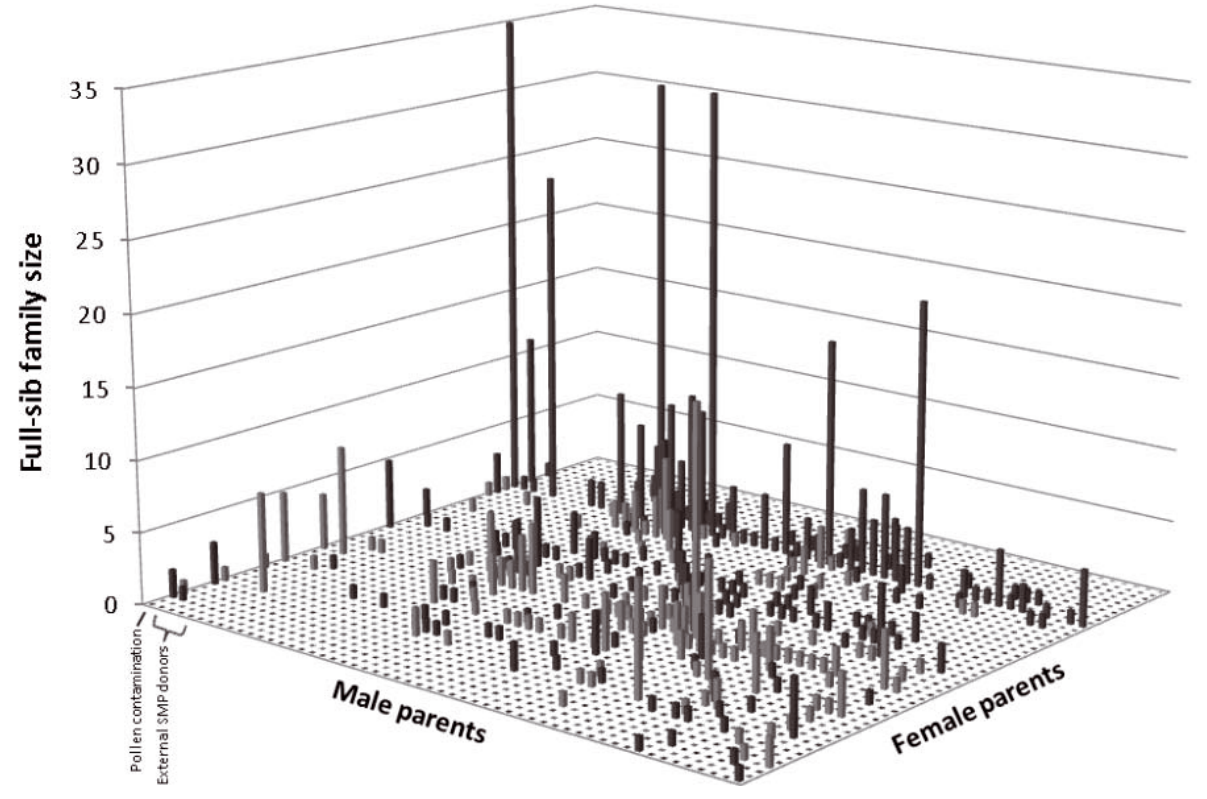

Figure 1. A 3-D representation of the mating dynamics in the studied Douglas-fir seed orchard. Each column represents the size of a unique full-sib family (vertical axis), i.e., the cross between a particular male and female parent (left and right horizontal axes, respectively). The five paternal parents on the left represent pollen contamination and four external pollen donors.

LiCor 4200 automated sequencer (LiCor Inc., Lincoln, NE). In order to reduce genotyping error, the amplicons were visually scored (genotyped) using SAGA ${ }^{\mathrm{TM}}$ software (LiCor Inc., Lincoln, NE) with the assistance of four 50-350 bp sizing standards (LiCor Inc., Lincoln, NE) and an artificial sample of orchard's "reference alleles." This sample was a product of amplification of DNA mixed from several parental genotypes and thus represented the parental population's allele range, which eased the scoring process. The megagametophyte (1n) and its corresponding embryo (2n) were concurrently scored for each seed.

\subsection{Data analysis}

Data analysis was based on a total of 801 seeds after excluding any seed (embryo or its corresponding megagametophyte) with more than four loci drop-outs caused by poor amplification. The multilocus genotype of each megagametophyte was independently used to determine the maternal parent using a computer program written in Microsoft VisualBasic ${ }^{\circledR}$ and the paternal parent of each embryo was assigned using the CERVUS program (Kalinowski et al., 2007) with 95\% assignment probability and allowance for genotyping errors. The assigned male and maternal parents of the 801 seeds were used to construct a 3-dimensional graph depicting the mating pattern across the orchard's mating landscape (Fig. 1). Seeds pollinated by the four external SMP donors and those by outside pollen sources (contamination) were also included in Figure 1. The result from the parentage assignment was used to estimate maternal, paternal and parental (maternal + paternal) reproductive success/contribution, selfing rate, the pollination success rate of the four external SMP donors, and the rate of pollen contamination. Additionally, the number of alleles, their frequencies, and their observed heterozygosities for each of the eight microsatellite loci studied were determined for both the parental and offspring populations.
Genetic diversity was estimated using effective population size, $N_{\mathrm{E}}$, which describes the proportion of parents involved in the production of the next generation (seed crop). Considering related individuals in the orchard, we employed the concept of group co-ancestry introduced by Cockerham (1967). Group co-ancestry $(\Theta)$ relates to the effective population size as:

$$
N_{\mathrm{E}}=\frac{1}{2 \Theta} \Longleftrightarrow N_{\mathrm{E}}=\frac{1}{2 \sum_{i=1}^{N} \Sigma_{j=1}^{N} p_{i} p_{j} c_{i j}}
$$

where $p_{i}$ and $p_{j}$ are proportional gametic contributions of parents $i$ and $j$ to the seed crop, respectively, and $c_{i j}$ is the co-ancestry between these parents. The co-ancestry coefficients are $0.5,0.25,0.25$, 0.125 and 0.0 for self co-ancestry, full-siblings, parent-offspring, half-siblings and individuals with no genetic relationship, respectively. The parental gametic contributions $\left(p_{i}\right)$ were split into their paternal $\left(m_{i}\right)$ and maternal $\left(f_{i}\right)$ components such that

$$
p_{i}=\left(\frac{f_{i}+m_{i}}{2}\right)
$$

where $\Sigma_{i=1}^{N} f_{i}=1$ and $\Sigma_{i=1}^{N} m_{i}=1$.

SMP success rate was estimated as follows: a quadratic regression model was developed to predict the ambient pollination success rate; the model was based on pollen production estimates (visual assessment) and actual pollination success for the 37 parents by the DNA analysis that were not included in SMP treatment (i.e., no confounding effects). Using this model, the ambient pollination success rate for the remaining 12 parents (internal pollen donors) was predicted and compared to the actual DNA results. The difference between them, after scaling the total within-orchard pollination success to $100 \%$ (this scaling was necessary to exclude seed pollinated by outside-orchard sources and the four external SMP donors), provided an estimate of the internal SMP success rate. Finally, the combined effect of pollen 
augmentation was estimated by adding the internal and external SMP success rates.

\section{RESULTS AND DISCUSSION}

\subsection{Pedigree reconstruction}

The pedigree reconstruction successfully assigned the maternal and paternal parents of the 801 seeds analyzed including those pollinated by either the four known external SMP donors or unknown pollen sources (Fig. 1). The eight microsatellite loci used, with their high allelic richness, were informative in unraveling the kinship relations in the studied sample of bulked seed. Figure 1 demonstrates all the information needed to obtain direct estimation of (1) maternal, paternal, and parental reproductive success, (2) selfing rate, (3) external SMP success rate, and (4) pollen contamination.

\subsection{Parental gametic contribution}

Accurate measure of parental reproductive success is a prerequisite for understanding the true pollination dynamics in this perceived to be "closed" population, for correctly estimating the expected genetic diversity in its seed crop, and for evaluating the impact of SMP treatment and bloom delay. Excluding the four external pollen donors, 46 and 42 out of the orchard's 49 clones participated as pollen and seed parents, respectively (Fig. 1). Maternal and paternal cumulative reproductive success (parental balance curves were presented following Griffin, 1982) indicated that $80 \%$ of the orchard's seed and pollen were contributed by 23 and $45 \%$ of parents, respectively (Fig. 2a), highlighting a greater maternal than paternal reproductive output distortion. Parental reproductive success (combined maternal and paternal) was also distorted; however, it was better than the " $80 / 20$ rule" commonly observed in many conifers seed orchards (Anonymous, 1976) with 80\% of the gametes produced by $37 \%$ of the orchard's population (Fig. 2a). As in recently conducted studies on conifer seed orchards (Funda et al., 2008; Hansen and Kjaer, 2006; Moriguchi et al., 2004, 2005; Slavov et al., 2005), the present study also demonstrated the usefulness of DNA fingerprinting in determining the difficult-to-measure paternal fertility variation.

\subsection{Genetic diversity}

Monitoring the genetic diversity over generations is important for determining the direction and magnitude of its change and understanding their causal factors such as fecundity variation, reproductive phenology asynchrony, inbreeding, and gene flow. Comparing the genetic diversity parameters between the orchard's parental population and its resultant seed crop indicated both gain and loss of alleles at some of the studied loci (Tab. I). Gain of alleles, which indicates gene flow from outside-orchard pollen sources, was observed at four loci (gain of 1 allele at PmOSU_3B9, PmOSU_2D4, and PmOSU_2G12 and 2 alleles at PmOSU_3F1). Similar observation was reported for an "interior" spruce seed orchard (El-Kassaby et al., 2007). Loss of 1 allele was observed at four loci (PmOSU_3B9, PmOSU_3D5, PmOSU_3F1, and PmOSU_3G9), pointing out that these alleles are rare and only belonged to a single parent that contributed minimally to the gene pool, thus they were not adequately represented in the analyzed seed sample.

The genetic diversity in a population can be estimated by effective population size, a measure of the average number of individuals in the population that contributes to the next generation (Wright, 1931). In an ideal population, the effective population size is expected to equal the actual population's census number. Using parental reproductive success estimates and after excluding pollen contamination, the maternal $\left(N_{\mathrm{ef}}\right)$, paternal $\left(N_{\mathrm{em}}\right)$, and parental $\left(N_{\mathrm{ec}}\right)$ effective population sizes were estimated to be $6.5,26.0,13.7$, respectively. These values are extremely low for a seed orchard population comprising of 42 females and 50 males successfully contributing to the offspring gene pool (see Fig. 1 for details and note that the orchard's census number was 49 and additional 4 external pollen donors were used) and are mainly the result of the extreme fertility variation (Fig. 2a). A small effective population size is expected to contribute to the build-up of inbreeding through higher-than-expected selfing and mating among relatives in the resultant seed crop as well as unreliable estimates of genetic gain and diversity (see selfing section below).

\subsection{Selfing}

Selfing in most conifer species results in poor seed set (Woods and Heaman, 1989), decreased progeny size, reduced progeny vigor and increased susceptibility to pests (Orr-Ewing, 1954, 1965; Sorensen, 1971). Under panmixia, a selfing rate of $2 \%$ is expected to occur in this seed orchard $\left(49 / 49^{2}\right)$; however, an estimate of $15.2 \%$ was detected. This value is higher than most selfing rates reported for this species' natural and/or seed orchard populations (El-Kassaby and Davidson, 1991; Ritland and El-Kassaby, 1985; Shaw and Allard, 1982; Slavov et al., 2005) and is unexpected for the following reasons: (1) pollination environment was manipulated by the bloom delay treatment which has been shown to promote outcrossing because all parents released their pollen within a limited timeframe (El-Kassaby and Davidson, 1991; El-Kassaby and Ritland, 1986; El-Kassaby et al., 1988), (2) SMP was used which also has been proven to increase outcrossing specifically if outside SMP donors were used (ElKassaby and Davidson, 1990), and (3) the seed orchard was exposed to external gene flow (see pollen contamination section below) which is expected to increase outcrossing because every successful pollen contamination event is an outcrossing event (El-Kassaby and Ritland, 1986). It could be speculated that SMP from the 12 internal parents unintentionally increased the selfing rate through application on donor clones; however, this possibility should be ruled out since pollen mixes were exclusively applied to non-pollen donors. The estimated selfing rate for the 12 internal SMP clones is essentially 
(a) Parental balance

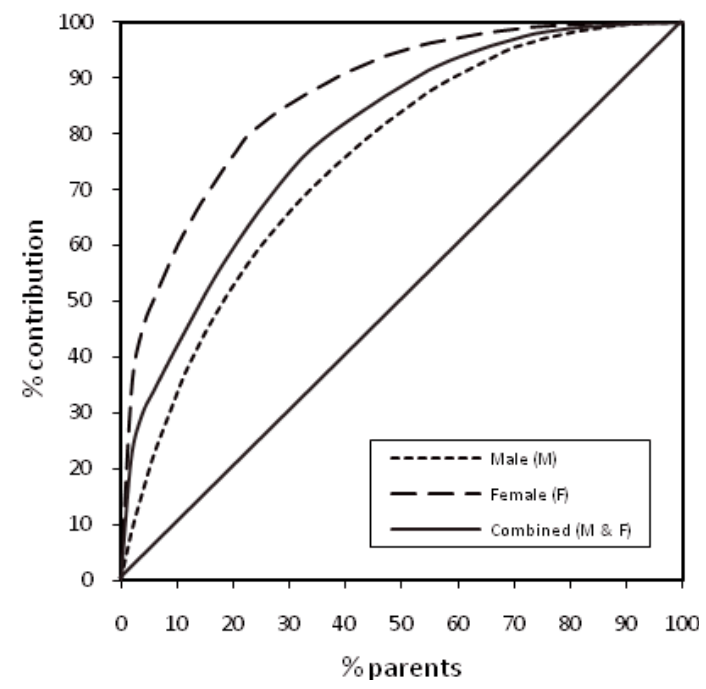

(b) Internal SMP evaluation

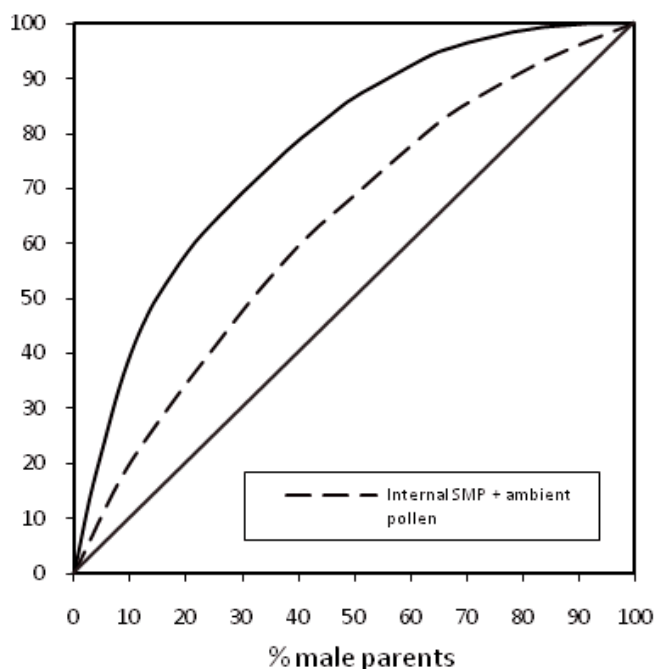

Figure 2. (a) Cumulative male, female, and combined male and female reproductive success for 53 male and 49 female parents and (b) a comparison between the orchard's ambient and ambient + internal SMP cumulative male reproductive success (37 and 12 male parents, respectively; external pollen donors excluded). The diagonal lines represent equal contribution among parents.

Table I. Genetic diversity of the seed orchard's parental and offspring populations estimated for each microsatellite locus by allelic richness $(A)$ and observed heterozygosity $\left(H_{O}\right)$.

\begin{tabular}{lcccc}
\hline \multirow{2}{*}{ Locus } & \multicolumn{2}{c}{ Parental population } & \multicolumn{2}{c}{ Seed crop } \\
\cline { 2 - 5 } & $A$ & $H_{O}$ & $A$ & $H_{O}$ \\
\hline PmOSU_2C2 $^{*}$ & 18 & 0.736 & 18 & 0.590 \\
PmOSU_3B9 $^{* * *}$ & 19 & 0.755 & 19 & 0.763 \\
PmOSU_3D5 $^{* *}$ & 15 & 0.533 & 14 & 0.384 \\
PmOSU_3F1 $^{* * * *}$ & 19 & 0.731 & 20 & 0.666 \\
PmOSU_2D4 $^{*}$ & 25 & 0.551 & 26 & 0.711 \\
PmOSU_2G12 $^{*}$ & 17 & 0.792 & 18 & 0.811 \\
PmOSU_1F9 $^{*}$ & 24 & 0.451 & 24 & 0.404 \\
PmOSU_3G9 $^{* *}$ & 24 & 0.660 & 23 & 0.695 \\
\hline
\end{tabular}

* Indicates gain of one allele

${ }^{* *}$ Indicates loss of one allele.

the same as for the whole orchard population (slightly below at $14.8 \%$ ), so SMP can be excluded as a cause of the observed high selfing rate. Additionally, the correlation between the 12 internal male donors' reproductive success and their selfing rate was significant ( $r=0.654, P<0.05, N=12$ ). Independent examination of the male reproductive success of these 12 clones indicated that all have contributed almost equally ( $80 \%$ of male gametes were produced by $63 \%$ of these 12 internal SMP parents), a substantial improvement compared to the entire orchard's population, which may be an indication of the positive role of SMP in balancing the paternal reproductive success (Fig. 2b).

While bloom delay has been reported to promote outcrossing through pollination period compaction, the high selfing rate observed in the present study could have been caused by the bloom delay's maximization of within clone synchrony, which created an environment for increased selfing. This scenario, while seemingly contradictory, clearly differentiates between among- and within-clone matings. This is the most plausible explanation for the observed high selfing rate and was further substantiated by the highly significant correlation coefficient between clonal reproductive success and selfing rate $(r=0.944, P<0.01, N=49)$. While polyembryony (Sorensen, 1982) and inbreeding depression (Orr-Ewing, $1954,1965)$ are expected to promote outcrossing by favouring embryos pollinated by unrelated individuals, the passive pollination mechanism of Douglas-fir which is characterized by the "first-on, first-in" concept (Franklin, 1974), could be responsible for the observed high selfing. In Douglas-fir, pollen is entrapped and engulfed by the stigmatic tips and subsequently delivered to the nucellus without any differentiation between self and unrelated pollen (Allen and Owens, 1972; Owens and Simpson, 1982; Owens et al., 1981). If self pollen is in a high frequency or exclusively present among those landed, engulfed, and delivered to the nucellus, then selfed embryos will develop even after competition and selection. Indeed, high selfing rates were reported for Douglas-fir on both the individual tree (Erickson and Adams, 1990; El-Kassaby et al., 1986) and population (multiple clone banks) level (Fast et al., 1986).

It is noteworthy to mention that while the observed selfing rate in the present study is seemingly high and ample biological evidence was provided to explain its occurrence, the commonly reported Douglas-fir "low" selfing rate used for comparison is also questionable. In the present study, a random sample of seed was drawn and used to determine, among other parameters, the selfing rate for this year's seed crop. This sample is a true representative of both the maternal and paternal reproductive success, thus the observed selfing rate should also be considered as representative of this year's mating events. This situation is different from all published 
Douglas-fir mating system studies where an equal number of seed (offspring) per parent/tree was used to create the family arrays needed for estimating the mating system parameters. The use of equal number of offspring per tree may mask and distort the true impact of variable reproductive output and yields unrealistic mating system and gene flow parameters, even if they are close to the true value. Denti and Schoen (1988) were the first to highlight the role of variable reproductive success on selfing rate and reported higher selfing rate in a white spruce (Picea glauca) seed orchard when reproductive success was considered.

\subsection{Supplemental mass pollination}

SMP success depends on many factors including (1) orchard age (Daniels, 1978), (2) number of pollen applications (El-Kassaby et al., 1993) and their timing (Owens et al., 1981), (3) stage of reproductive phenology (El-Kassaby and Ritland, 1986), (4) other crop management practices applied such as bloom delay (El-Kassaby and Ritland, 1986), (5) density of within-orchard pollen cloud (Nakamura and Wheeler, 1992), (6) level of pollen contamination (El-Kassaby and Ritland, 1986), (7) quality and quantity of SMP pollen (Webber and Painter, 1996), and (8) fluctuation of cone crop (poor vs. good cone year).

Since the paternity analysis was conducted on a bulk seed sample, then SMP success rate could only be estimated on the clonal rather than individual ramet level and the impact of multiple applications could not be ascertained. For the four external pollen donors, the SMP success rate was definitively estimated to be 5.4\%. However, for the 12 internal SMP donors, the SMP success rate could not be parsed out from that of their ambient contribution as they contributed to the orchard's pollen cloud in two ways: by ambient and supplemented pollen. Therefore, the SMP success rate of these 12 donors had to be estimated using a prediction model (see Section 2) and was determined to be equal to $9.6 \%$. Finally, the aggregate success rate of the internal and external SMP was estimated to be equal to $15.0 \%$ in this study $(5.4+9.6=$ $15.0 \%)$. This value is higher than that reported by El-Kassaby et al. (1993) for one application $(8.3 \%)$ and lower than the average expectations of $25 \%$ proposed by Stoehr et al. (2004) and Woods (2005), but it corresponded well with the $16 \%$ reported by Stoehr et al. (2006) in a lodgepole pine seed orchard study. Bridgwater et al. (1993) and El-Kassaby et al. (1993) determined that the SMP success rate is greatly affected by timing, number, and method of applications (see above).

\subsection{Gene flow}

Gene flow from extraneous pollen sources to seed orchards, or pollen contamination, plays a counterproductive role to the main objectives of tree breeding programs (Adams et al., 1997). However, in some cases when the impact of pollen contamination is adaptively neutral (i.e., no detrimental adaptive effect), pollen contamination is perceived as a mean for increasing genetic diversity (Lindgren and Mullin, 1998). Seed orchard location and the genetic quality of the contaminant pollen source(s) determine the degree and extent of the genetic impact of pollen contamination on the resultant seed crops. A relatively high pollen contamination detected in this study $(\approx 10.4 \%)$ is almost double of that reported by El-Kassaby and Ritland (1986) for another seed orchard crop managed under the similar conditions and at the same location. Although the rate of pollen contamination is orchard-crop specific, the difference between these two studies could be attributed to the genetic markers used. El-Kassaby and Ritland (1986) used allozyme markers which could have underestimated the effective contamination rate due to their limited allelic number, hence affecting the degree of contamination detected. On the other hand, this estimate could be viewed as support for the effective crop management applied when compared to the $35 \%$ reported for a Douglas-fir seed orchard's crop produced under no bloom delay and supplemental-mass-pollination, using the same genetic markers (Slavov et al., 2005). It should be stated that our study orchard is located on site where potential local contamination sources are limited and therefore long distance gene flow should be considered as the main source of contamination.

\subsection{Mislabeling errors}

By capitalizing on microsatellite multilocus genotyping resolution power, we identified a single incident of a mislabeled ramet within the 149 fingerprinted ramets, indicating that $99.3 \%$ of the orchard's parents were correctly labeled. The multilocus genotype of the mislabeled ramet was informative and allowed for identification of its correct ortet (clone). Since this genotype was already present in the orchard, no further adjustment was needed for all subsequent analyses. Mislabeling of ramets in seed orchards is common (Adams et al., 1988; Slavov et al., 2004); thus, parental verification of seed orchards is recommended specifically if their trees are used for breeding purposes.

Acknowledgements: Funds from the Johnson's Family Forest Biotechnology Endowment, the British Columbia Forest Investment Account Forest Genetic Conservation and Management program, the Natural Sciences and Engineering Research Council of Canada - Discovery and the IRC grants to YAK, the Natural Resources CanadaScience and Technology Internship Program to Ben Sk Lai, and the Czech Science Foundation (research grant \#521/07/P337) to Jaroslav Klápště are greatly appreciated.

\section{REFERENCES}

Adams W.T., Neale D.B., and Lopstra C.A., 1988. Verifying controlled crosses in conifer tree-improvement programs. Silvae Genet. 37: $147-152$.

Adams W.T., Hipkins V.D., Burczyk J., and Randall W.K., 1997. Pollen contamination trends in a maturing Douglas-fir seed orchard. Can. J. For. Res. 27: 131-134. 
Allen G.S. and Owens J.N., 1972. The Life History of Douglas-fir, Ottawa, Canada, Can. For. Serv. 139 p.

Anonymous, 1976. Twentieth annual report on cooperative tree improvement and hardwood research program, North Carolina State University, Raleigh, USA.

Askew G.R., 1992. Potential genetic improvement due to supplemental mass pollination management in conifer seed orchards. For. Ecol. Manage. 47: 135-147.

Bell G.D. and Fletcher A.M., 1978. Computer organised orchard layouts (COOL) based on the permutated neighbourhood design concept, Silvae Genet. 27: 223-225.

Bridgwater F.E., Bramlett D.L., and Matthews F.R., 1987. Supplemental mass pollination is feasible on an operational scale. In: Proc. 19th South. For. Tree Improv. Conf., College Sta, TX, pp. 216-222.

Cockerham C., 1967. Group inbreeding and coancestry. Genetics 56: 89104

Daniels J.D., 1978. Efficacy of supplemental mass pollination in a Douglas-fir seed orchard. Silvae Genet. 27: 52-58.

Denti D., Schoen D.J., 1988. Self-fertilization rates in white spruce: effect of pollen and seed production. J. Hered. 79: 284-288.

Doyle J.J. and Doyle J.L., 1990. Isolation of plant DNA from fresh tissue. Focus 12: 13-15.

Edwards D.G.W. and El-Kassaby Y.A., 1995. Douglas-fir genotypic response to seed stratification. Seed Sci Tech. 23: 771-778.

El-Kassaby Y.A., 1992. Domestication and genetic diversity - should we be concerned? For. Chron. 68: 687-700.

El-Kassaby Y.A. and Askew G.R., 1998. Seed orchards and their genetics. In: Mandal A.K., Gibson G.L. (Ed.), Forest genetics and tree breeding, CBS Publishers and Distributors, Daryaganj, New Delhi, India, pp. 103-111.

El-Kassaby Y.A. and Davidson R., 1990. Impact of crop management practices on the seed crop genetic quality in a Douglas-fir seed orchard. Silvae Genet. 39: 230-237.

El-Kassaby Y.A. and Davidson R. 1991. Impact of pollination environment manipulation on the apparent outcrossing rate in a Douglas-fir seed orchard. Heredity 66: 55-59.

El-Kassaby Y.A. and Ritland K., 1986. The relation of outcrossing and contamination to reproductive phenology and supplemental mass pollination in a Douglas-fir seed orchard. Silvae Genet. 35: 240-244.

El-Kassaby Y.A., Parkinson J., and Devitt W.J.B., 1986. The effect of crown segment on the mating system in a Douglas-fir (Pseudotsuga menziesii (Mirb.) Franco) seed orchard. Silvae Genet. 35: 149-155.

El-Kassaby Y.A., Ritland K., Fashler A.M.K., and Devitt W.J.B., 1988. The role of reproductive phenology upon the mating structure of a Douglas-fir seed orchard. Silvae Genet. 37: 76-82.

El-Kassaby Y.A., Edwards D.G.W., and Cook C., 1990. Impact of crop management practices on seed yield in a Douglas-fir seed orchard. Silvae Genet. 39: 226-230.

El-Kassaby Y.A., Barnes S., Cook C., and MacLeod D.A., 1993. Supplemental mass pollination success rate in a mature Douglas-fir seed orchard. Can. J. For. Res. 23: 1069-1099.

El-Kassaby Y.A., Stoehr M.U., Reid D., Walsh C.G., and Lee T.E., 2007. Clonal-row versus random seed orchard designs: interior spruce mating system evaluation. Can. J. For. Res. 37: 690-696.

Erickson V.J. and Adams W.T., 1990. Mating system variation among individual ramets in a Douglas-fir seed orchard. Can. J. For. Res. 20: $1672-1675$.

Eriksson G., Jonsson A., and Lindgren D., 1973. Flowering in a clonal trial of Picea abies Karst. Stud. For. Suec. 110: 3-45.

Fashler A.M.K. and Devitt W.J.B., 1980. A practical solution to Douglasfir seed orchard pollen contamination. For. Chron. 56: 237-240.
Fashler A.M.K. and El-Kassaby Y.A., 1987. The effect of water spray cooling treatment on reproductive phenology in a Douglas-fir seed orchard. Silvae Genet. 36: 245-249.

Fast W., Dancik B.P., and Bower R.C., 1986. Mating system and pollen contamination in a Douglas-fir clone bank. Can. J. For. Res. 16: $1314-1319$.

Franklin E.C., 1974. Pollination in slash pine: first come, first served. In: Proceedings of a Colloquium, Seed yield from southern pine seed orchards In: Kraus J. (Ed.), Georgia Forestry Center, Macon, GA, pp. $15-20$.

Funda T., Chen C., Liewlaksaneeyanawin C., Kenawy A., and El-Kassaby Y.A., 2008. Pedigree and mating system analyses in a western larch (Larix occidentalis Nutt.) experimental population. Ann. For. Sci. 65: 705.

Griffin A.R., 1982. Clonal variation in radiata pine seed orchards. I. Some flowering, cone and seed production traits. Aust. For. Res. 12: 295302.

Hansen O.K. and Kjaer E.D., 2006. Paternity analysis with microsatellites in a Danish Abies nordmanniana clonal seed orchard reveals dysfunctions. Can. J. For. Res. 36: 1054-1058.

Kalinowski S.T., Taper M.L., and Marshall T.C., 2007. Revising how the computer program CERVUS accommodates genotyping error increases success in paternity assignment. Mol. Ecol. 16: 1099-1106.

Krutovskii K.V., Vollmer S.S., Sorensen F.C., Adams W.T., and Strauss S.H., 1997. Effects of megagametophyte removal on DNA yield and early seedling growth in coastal Douglas-fir. Can. J. For. Res. 27: 964-968.

Lindgren D. and Mullin T.J., 1998. Relatedness and status number in seed orchard crops. Can. J. For. Res. 28: 276-283.

Moriguchi Y., Taira H., Tani N., and Tsumura Y., 2004. Variation of paternal contribution in a seed orchard of Cryptomeria japonica determined using microsatellite markers. Can. J. For. Res. 34: 1683-1690.

Moriguchi Y., Tani N., Itoo S., Kanehira F., Tanaka K., Yomogida H., Taira H., and Tsumura Y., 2005. Gene flow and mating system in five Cryptomeria japonica D. Don seed orchards as revealed by analysis of microsatellite markers. Tree Genet. Genomes. 1: 174-183.

Nakamura R.R. and Wheeler N.C., 1992. Pollen competition and paternal success in Douglas-fir. Evolution 46: 846-851.

Namkoong G., Kang H.C., and Brouard J.S., 1988. Tree breeding: principles and strategies, Monographs on theoretical and applied genetics. II, Springer-Verlag, New York, USA.

Orr-Ewing A.L., 1954. Inbreeding experiments with the Douglas-fir. For. Chron. 30: 7-21.

Orr-Ewing A.L., 1965. Inbreeding and single-crossing in Douglas-fir. For. Sci. 11: 279-290.

Owens J.N. and Simpson S.J., 1982. Further observations on the pollination mechanism and seed production of Douglas-fir. Can. J. For. Res. 12: $431-434$.

Owens J.N., Simpson S.J., and Molder M., 1981. The pollination mechanism and the optimal time of pollination in Douglas-fir (Pseudotsuga menziesii). Can. J. For. Res. 11: 36-50.

Ritland K. and El-Kassaby Y.A., 1985. The nature of inbreeding in a seed orchard of Douglas-fir as shown by an efficient multilocus model. Theor. Appl. Genet. 71: 375-384.

Shaw D.V. and Allard R.W., 1982. Estimation of outcrossing rates in Douglas-fir using isozyme markers. Theor. Appl. Genet. 62: 113120.

Silen R.R. and Keane G., 1969. Cooling a Douglas-fir seed orchard to avoid pollen contamination, USDA For. Serv. Res. Note PNW-101.

Slavov G.T., Howe G.T., and Adams W.T., 2005. Pollen contamination and mating patterns in a Douglas-fir seed orchard as measured by simple sequence repeat markers. Can. J. For. Res. 35: 1592-1603. 
Slavov G.T., Howe G.T., Yakovlev I., Edwards K.J., Krutovskii K.V., Tuskan G.A., Carlson J.E., Strauss S.H., and Adams W.T., 2004. Highly variable SSR markers in Douglas-fir: Mendelian inheritance and map locations. Theor. Appl. Genet. 108: 873-880.

Sorensen F.C., 1971. Estimate of self-fertility in coastal Douglas-fir from inbreeding studies. Silvae Genet. 20: 115-120.

Sorensen F.C., 1982. The roles of polyembryony and embryo viability in the genetic system of conifers. Evolution 36: 725-733.

Stoehr M.U. and Newton C.H., 2002. Evaluation of mating dynamics in a lodgepole pine seed orchard using chloroplast DNA markers. Can. J. For. Res. 32: 469-476.

Stoehr M.U., Orvar B.L., Vo T.M., Gawley J.R., Webber J.E., and Newton C.H., 1998. Application of a chloroplast DNA marker in seed orchard management evaluations of Douglas-fir. Can. J. For. Res. 28: 187195.

Stoehr M.U., Webber J.E., and Woods J.H., 2004. Protocol for rating seed orchard seedlots in British Columbia: quantifying genetic gain and diversity. Forestry 77: 297-303.

Stoehr M.U., Mehl H., Nicholson G., Pieper G., and Newton C.H., 2006. Evaluating supplemental mass pollination efficacy in a lodgepole pine orchard in British Columbia using chloroplast DNA markers. New For. 31: 83-90.
Wakeley P.C., Wells O.O., and Campbell T.E., 1966. Mass production of shortleaf $\times$ slash pine hybrids by pollinating unbagged female flowers. In: Joint Proceedings of the Second Genetics Workshop of the Society of American Foresters and the Seventh Lake States Forest Tree Improvement Conference, USDA Forest Service, St. Paul, USA, Res. Pap. NC-6, pp. 78-79.

Webber J.E. and Painter R.A., 1996. Douglas-fir pollen management manual. Second edition, Res. Program WP 02/96. B.C. Ministry of Forests, Victoria, Canada.

Woods J.H., 2005. Methods for estimating gamete contributions to orchard seed crops and vegetative lots in British Columbia. B.C. Ministry of Forests and Range, Research Branch, Victoria, B.C. Tech Rep 25.

Woods J.H. and Heaman J.C., 1989. Effect of different inbreeding levels on filled seed production in Douglas-fir. Can. J. For. Res. 19: 54-59.

Wright S., 1931. Evolution in Mendelian populations. Genetics 16: 97159.

Yazdani R., Hadders G., and Szmidt A., 1986. Supplemental mass pollination in a seed orchard of Pinus sylvestris L. investigated by isozyme analyses. Scand. J. For. Res. 1: 309-315. 